Çukurova Üniversitesi Mühendislik Mimarlık Fakültesi Dergisi, 35(1), ss. 67-78, Mart 2020

Çukurova University Journal of the Faculty of Engineering and Architecture, 35(1), pp. 67-78, March 2020

\title{
Metamalzeme Yapılarıyla Fraktal Anten Parametrelerinin İyileştirilmesi
}

\author{
Emin $\ddot{U} N A L^{*}$, Ceren DOĞAN $N^{l}$ \\ ${ }^{1}$ Iskenderun Teknik Üniversitesi, Mühendislik ve Doğa Bilimleri Fakültesi, Elektrik-Elektronik \\ Mühendisliği Bölümü, Hatay
}

Geliş tarihi: 06.07.2019 Kabul tarihi: 15.05 .2020

\section{$\ddot{O} z$}

$\mathrm{Bu}$ çalışmada 5,47 GHz'de çalışan bir fraktal anten tasarımı yapılmış ve bu antenin yönlülüğünün, kazancının ve verimliliğ̈inin Metamalzemeli yapılar kullanılarak iyileştirilmesi amaçlanmıștır. FIT tabanlı simülasyon programı yardımıyla dairesel şekillerden oluşmuş ve her daire arasındaki oran sabit 0,65 olan bir fraktal anten tasarlanmıştır. Her biri $38 \mathrm{~mm}$ x $38 \mathrm{~mm}$ boyutunda, $2 \times 4$ birim hücreli eşkenar dörtgen yapılardan oluşmuş olan MTM yapısı yine aynı simülasyon programında tasarlanmıştır. MTM yapıların simülasyon sonucunda elde edilen S11 ve S21 parametre değerleri kullanılarak, yapının etkin dielektrik sabiti, etkin manyetik geçirgenliği ve kırılma indisi hesaplanmış ve hesaplanan bu değerlerin negatif olduğu görülmüştür. Metamalzemesiz fraktal antenin S11 değeri 5,47 GHz'de-16,973 dB iken, 2 MTM yapıs1 ile bu değer $-25,908 \mathrm{~dB}$ değerine kadar düşmüştür. Ayrıca, antenin yönlülüğü $6,65 \mathrm{dBi}$ 'den 9,67 dBi'ye, kazancı ise 1,19 dB'den 5,99 dB'ye yükselmiştir. Fraktal anten ve MTM'li yapının fabrikasyonları yapılmış olup, farklı sayılarda MTM yapısı anten üzerine 90 derece gelecek şekilde monte edilmiş ve ölçüm sonuçları elde edilmiştir. Ölçüm sonuçları ile simülasyon sonuçları karşılaştırılmış ve simülasyon sonuçları ile ölçüm sonuçlarının birbiri ile uyum içerisinde olduğu görülmüştür.

Anahtar Kelimeler: Metamalzeme, Fraktal anten, Minyatürleşme, Ultra geniş bant

\section{Improvement of Fractal Antenna Parameters with Metamaterial}

\begin{abstract}
In this study, a fractal antenna operating at $5.47 \mathrm{GHz}$ has been designed and it is aimed to improve the directivity, gain and efficiency of this antenna by using Metamaterials. With the help of a FIT-based simulation program, a fractal antenna consisting of circular shapes with a fixed ratio of 0.65 between each circle is designed. The MTM structure, which is composed of $2 \times 4$ unit cell rhombus structures, each of $38 \mathrm{~mm} \times 38 \mathrm{~mm}$, is designed in the same simulation program. Using the S11 and S21 parameter values obtained from the simulation of MTM structures, effective dielectric constant, effective magnetic permeability and refractive index of the structure are calculated and these values are found to be negative. While the S11 value of the fractal antenna without MTM is $-16.973 \mathrm{~dB}$ at $5.47 \mathrm{GHz}$, it has decreased to $-25.908 \mathrm{~dB}$ with $2 \mathrm{MTM}$ structures. In addition, the antenna's directivity has increased from $6.65 \mathrm{dBi}$ to
\end{abstract}

*Sorumlu yazar (Corresponding author): Emin ÜNAL, emin.unal@iste.edu.tr 
$9.67 \mathrm{dBi}$ and its gain has increased from $1.19 \mathrm{~dB}$ to $5.99 \mathrm{~dB}$. Fractal antenna and MTM structure are fabricated, different numbers of MTM structure have been mounted on antenna at 90 degrees and measurement results are obtained. Measurement results and simulation results are compared and it is seen that the simulation results and the measurement results are in good agreement with each other.

Keywords: Metamaterial, Fractal antenna, Miniaturization, Ultra-wide band

\section{GİRİŞ}

Fraktal kelimesi ilk olarak Polonya as1ll matematikçi Benoit Mandelbrot tarafindan 1975 yılında ortaya atılmıştır [1]. Fraktal yapılar bir şeklin orantılı olarak küçültülmesi veya büyütülmesi ile elde edilen yapıların periyodik olarak tekrarlanmasıyla elde edilen karmaşı yapılardır. Fraktal şekillerin kullanım alanlarından birisi de antenlerdir. Fraktal anten geleneksel antenlere kıyasla daha fazla avantaja sahiptir. Düşük maliyetli olan bu antenler küçük kesit alanına, çoklu rezonans frekansına ve büyük bant genişliğine sahiptirler. $\mathrm{Bu}$ antenlerin bir başka avantajı ise empedans eşleştirmeye gerek duymamasıdır. Dezavantajları ise karmaşık yapıya sahiptir ve bazı durumlarda düşük kazanca neden olabilirler. Fraktal geometrilerin yineleme sayısı arttıkça rezonans frekansları arasındaki mesafe azalmaktadır [2]. Fraktal antenler boşluk doldurma özelliği sayesinde minyatürleşmeye neden olurken, kendine benzerlik özelliği ile de geniş bir frekans dizisine sahiptirler. Savunma, askeri, uzay iletişim sistemleri, Wi-Fi, kablosuz yerel ağı (WLAN), mobil iletişim sistemleri çoklu frekans bandında çalışabilmesi için geniş bantlı antenlere ihtiyaç duyar [3].

Fraktal antenlerin yineleme sayısı ile ilgili 2013 yılında Jena ve arkadaşları Sierpinski Halı geometrisine dayanan fraktal anten tasarımı yapmış ve simülasyonunu gerçekleştirmiştir. Bu çalışmanın sonucunda yineleme sayısı arttıkça antenin kazancında iyileşme meydana geldiği görülmüştür [4]. 2015 yılında yapılan diğer bir çalışmada ise fraktal tabanlı mikroşerit yama anteni tasarlanmış ve bunun sonucunda çoklu rezonans elde edilmiştir. Tasarlanan antenin Ultra Geniş bant (UWB) uygulamaları için kullanışlı olduğu ifade edilmiştir [5]. Başka bir çalışmada ise Ultra geniş bant altıgen fraktal anten tasarımı, üretimi, ölçümü yapılmıştır. Bu anten tasarımında fraktal geometrisi, kenarlarında Koch kar tanesi bulunan altıgen şekil kullanılarak elde edilmiştir. Antenin bant genişliğinin ve kazancının fraktal geometri sayesinde arttığı görülmüştür [6]. CPW beslemeli UWB Gosper adası altıgen monopol anten tasarımı yapılmış ve standart antene kıyasla bant genişliğinin arttığı görülmüştür [7]. Madhav ve arkadaşları 2018 yılında $U$ ve W şeklinde fraktal anten tasarlamışlardır. $\mathrm{U}$ ve $\mathrm{W}$ şeklindeki yuvaların attırılması ile çok bantlı bir yapı elde edilmiştir [8]. Yong ve Shaobin, 2008 yılında yaptıkları çalışmada kare yapıların içerisinden, kare kenarlarının yarısına eşit yarıçaplı dairesel parçaları çıkartarak elde ettikleri yeni taç kare fraktal anten yapısını kullanmışlardır. $\mathrm{Bu}$ çalışmada, yineleme sayısı arttıkça rezonans sayısının arttığı not edilmiş ve ayrıca bant genişliğini kontrol etmenin mümkün olduğu ifade edilmiştir [9].

\section{MATERYAL VE METOT}

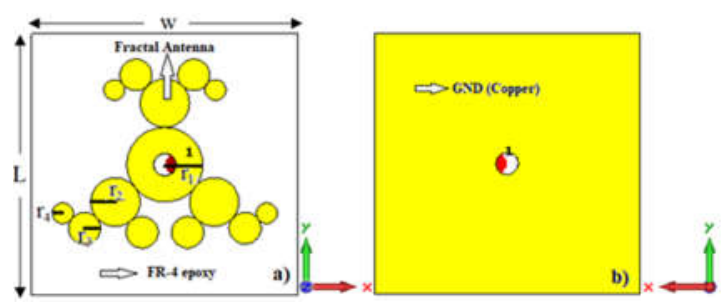

Şekil 1. Fraktal antenin görünümü; (a) ön, (b) arka

Şekil 1'de görülen fraktal antenin boyutları Çizelge 1'de verilmiştir. Fraktal antenin arka yüzeyinde kullanılan $35 \mathrm{~mm}$ x $35 \mathrm{~mm}$ bakır düzlemin kalınl $\breve{g ̆}_{1} 0,035 \mathrm{~mm}$ ve elektriksel iletkenliği $5,8001 \times 10^{7} \quad \mathrm{~S} / \mathrm{m}$ 'dir. Dielektrik malzeme olarak ise iyi performansa ve düşük maliyete sahip olan 1,6 mm kalınlığında, $\varepsilon r=4,4$, $\mu \mathrm{r}=1$ ve dielektrik kayıp tanjantı $\delta \varepsilon=0,02$ olan FR4-epoxy malzemesi seçilmiştir. Besleme için en 
büyük dairenin ortasından $1,5 \mathrm{~mm}$ yarıçapında oyuk açılmış ve fraktal şekil ile arkadaki metal düzleme temas edecek şekilde port atanmıştır.

Çizelge 1. Fraktal antenin 5,47 GHz için boyutları

\begin{tabular}{|l|l|}
\hline Anten parametreleri & Boyut \\
\hline Frekans & $5,47 \mathrm{GHz}$ \\
\hline Fraktal şekil, büyük daire $\left(\mathrm{r}_{1}\right)$ & $5 \mathrm{~mm}$ \\
\hline Fraktal şekil küçük daire $\left(\mathrm{r}_{2}\right)$ & $5 \times 0,65 \mathrm{~mm}$ \\
\hline $\mathrm{r}_{3}$ & $2,112 \mathrm{~mm}$ \\
\hline $\mathrm{r}_{4}$ & $1,373 \mathrm{~mm}$ \\
\hline Plaka uzunluğu $(\mathrm{L})$ & $35 \mathrm{~mm}$ \\
\hline Plaka genişliği $(\mathrm{W})$ & $35 \mathrm{~mm}$ \\
\hline Plaka kalınlığ 1 & $1,635 \mathrm{~mm}$ \\
\hline
\end{tabular}

Tasarımı yapılan fraktal anten FIT tabanlı simülasyon programı kullanılarak analiz edilmiş ve yansıma katsayısı (S11) Şekil 2'de görüldüğü gibi, $5,47 \mathrm{GHz}$ 'de $-16,947 \mathrm{~dB}$ olarak elde edilmiştir. S11 grafiği aynı zamanda antenin bant genişliğinin belirlenmesinde de kullanılmaktadır. Önerilen Fraktal antenin bant genişliği $(\mathrm{S} 11<-10 \quad \mathrm{~dB})$ yaklaşı olarak $146 \mathrm{MHz}$ 'dir.

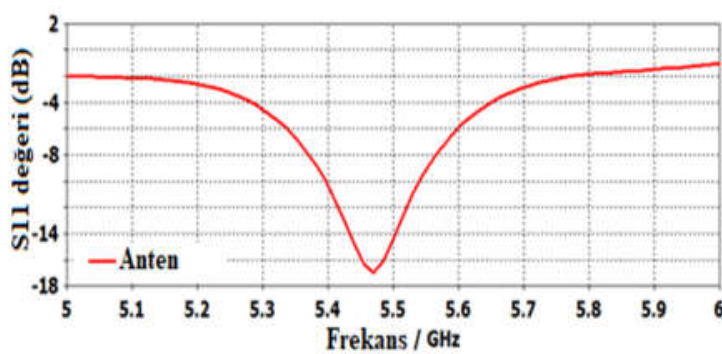

Şekil 1. Fraktal antenin sayısal olarak elde edilen S11 grafiği
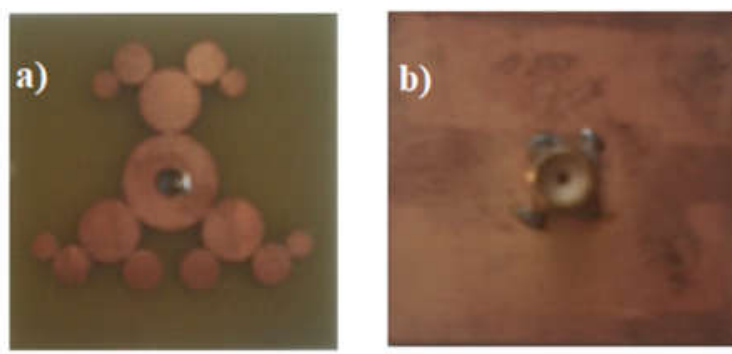

Şekil 2. Üretilen anten görünümü (a) ön, (b) arka
Üretimi gerçekleștirilen fraktal antenin ön ve arka yüzü Şekil 3'de görülmektedir. Önerilen fraktal anten için yansıma katsayısının sayısal ve ölçüm sonuçları Şekil 4'te verilmiştir. Rezonans frekansındaki kayma üretim ve ölçüm hatalarından kaynaklanmaktadır.

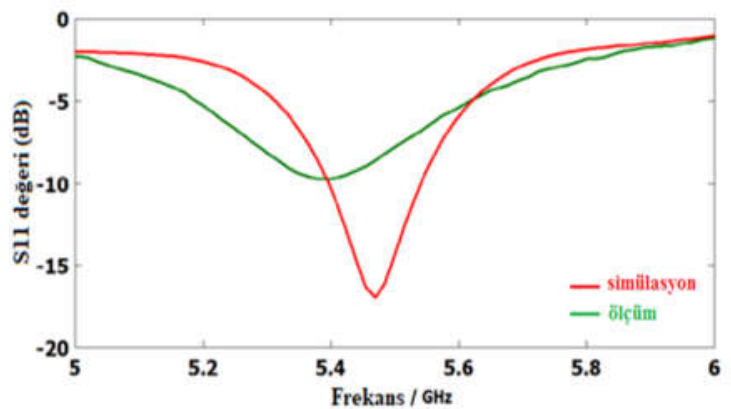

Şekil 4. Fraktal antenin sayısal ve deneysel S11 grafiği

Antenin verimini, yönlülüğünü ve kazancını belirleyebilmek için antenin radyasyon örüntüsü de incelenmelidir. Şekil 5'de antenin 2 ve 3 boyutlu uzak alan ışıması verilmiştir.

(a)

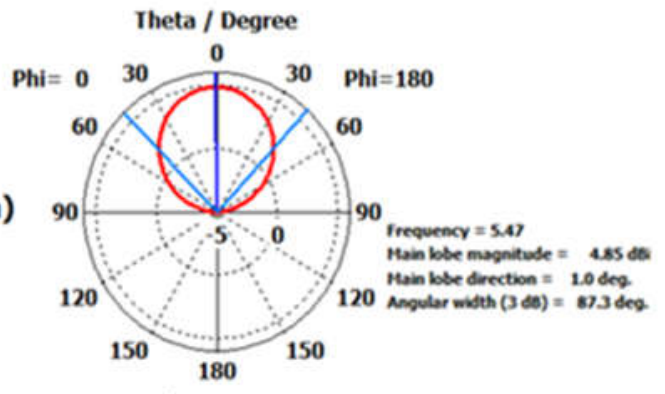

(b)

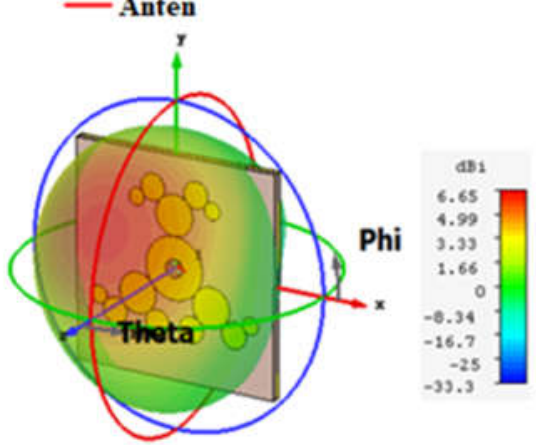

Şekil 5. Fraktal antenin Phi $=0$ derecede uzak alan ışıma eğrisi (a) 2 boyutlu (b) üç boyutlu 
Şekil 5a incelendiğinde, antenin ana lobu için 1şıma büyüklüğü, Phi= 0 derecede, $4,85 \mathrm{dBi}$, hüzme açısı $87,3^{\circ}$ olarak görülmek, ancak yan loblarda 1şıma görülmemektedir. Antenin yönlülüğü ise Şekil 5b'de görüldüğü gibi $6,65 \mathrm{dBi}$ ve kazanc1 1,19 dB'dir.

\section{MTM TASARIMI}

Metamalzemeler (MTM); doğada bulunmayan, laboratuvar ortamında yapay olarak üretilebilen, periyodik yapılardan meydana gelen malzemelerdir. Elektrik alan vektörü $(\vec{E})$, manyetik alan vektörü $(\vec{H})$ ve dalga vektörü $(\vec{k})$ bu ortamda sol el kuralına uymaktadır. Bu yüzden bu malzemelere sol el yönlü malzemeler (LHM) denir. Bu yapay malzemeler eş zamanlı olarak negatif etkin dielektrik sabitine $(\varepsilon)$, negatif manyetik geçirgenliğe $(\mu)$ ve negatif kırılma indisine (n) sahiptirler.

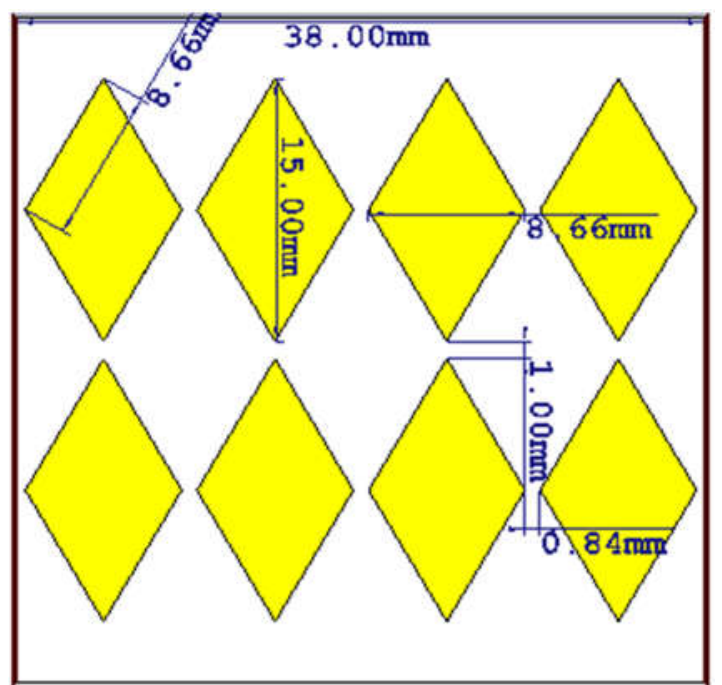

Şekil 6. Metamalzeme yapısının önden görünüşü

Dielektrik malzeme olarak $38 \mathrm{mmx} 38 \mathrm{~mm}$ boyutunda dielektrik geçirgenliği 4,3, manyetik geçirgenliği 1, dielektrik kayıp tanjant değeri 0,025 ve kalınlığı 1,6 mm olan FR4-epoxy seçilmiştir. FR4 malzemenin yüzeyi bakır olup kalınlığı $0,035 \mathrm{~mm}$ ve elektriksel iletkenliği ise $5,8001 \times 10^{7}$ S/m'dir. Tasarlanan MTM yapıları, Şekil 6'da görüldüğü gibi dielektrik yüzey üzerine $2 \times 4$ periyodik olarak birbirinin aynısı eşkenar dörtgen yapıların yerleştirilmesiyle oluşmuştur. Her bir eşkenar dörtgenin kenar uzunluğu 8,66 mm'dir.
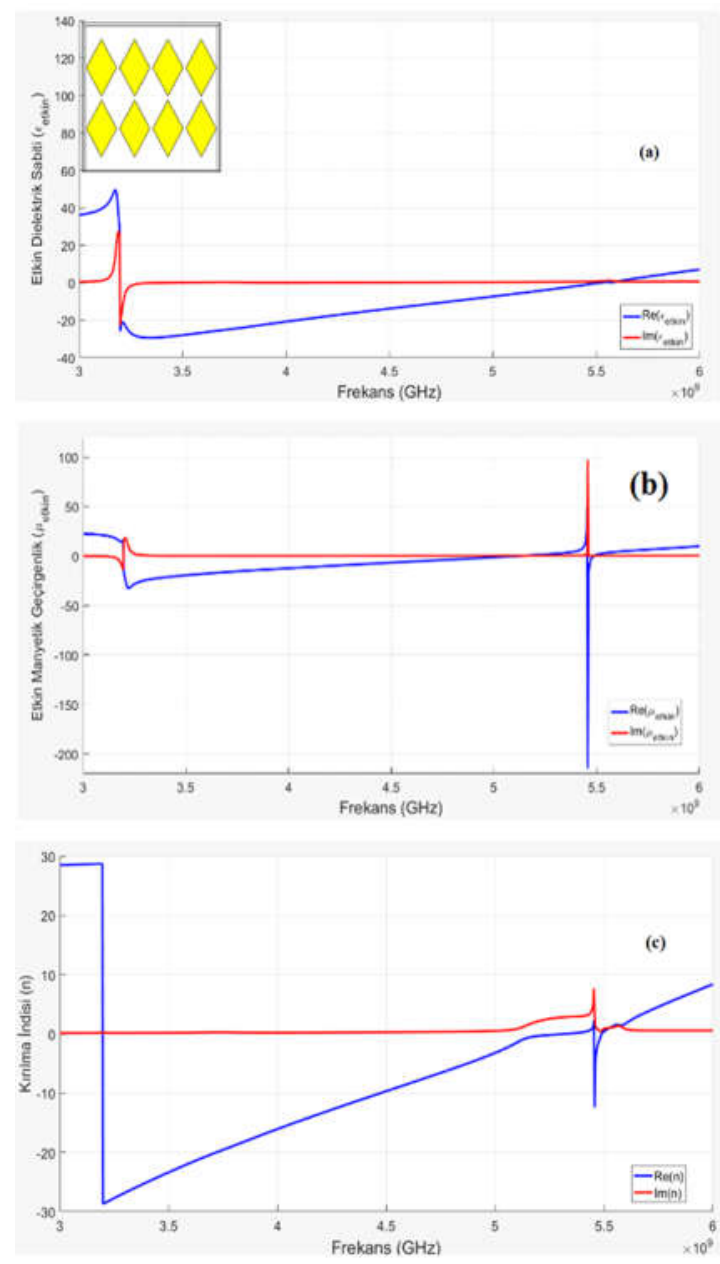

Şekil 7. Eşkenar dörtgen MTM yapısının reel ve sanal (a) manyetik geçirgenlik, (b) dielektrik geçirgenlik ve (c) kırılma indisi

Tasarlanan MTM yapısının sanal ve reel etkin manyetik geçirgenliği, etkin dielektrik sabiti, kırılma indisinin grafikleri Şekil 7'de verilmiştir. Sol-elli metamalzeme kullanılacak antenin çalışma frekansı 5,47 GHz'dir. MTM yapısının dielektrik sabiti, manyetik geçirgenlik ve kırılma indisi değerleri yaklaşık $3 \mathrm{GHz}-5.5 \mathrm{GHz}$ arasında eş zamanlı negatif olduğu görülmektedir ve antenin çalışma frekansı bu aralıkta yer almaktadır. 
Tasarlanan MTM yapısı fraktal anten üzerine, anten yüzeyine 90 derece olacak şekilde farklı sayılarda ve farklı konumlarda yerleştirilmiş ve her bir konfigürasyon için sayısal ve ölçüm sonuçları elde edilmiştir.
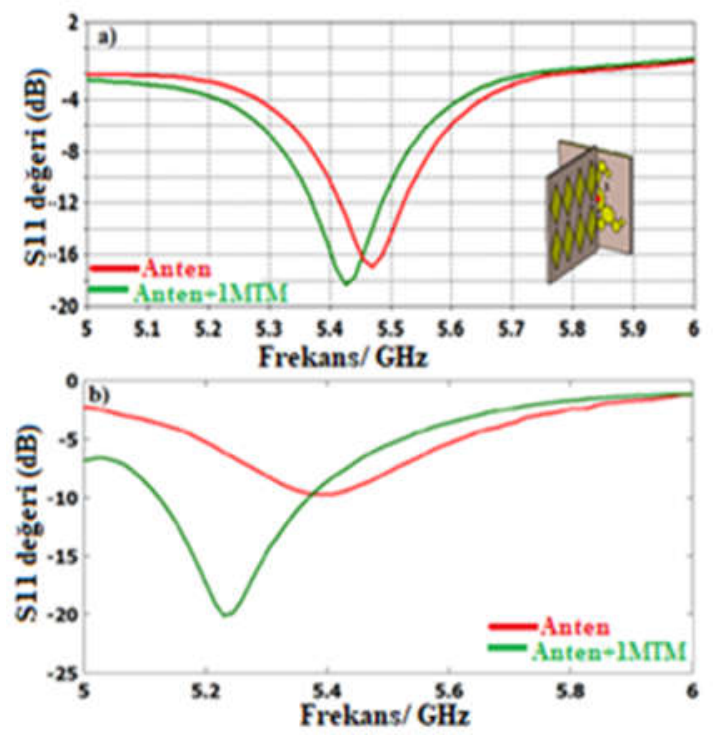

Şekil 8. Anten ve 1 MTM yapının S11 grafiği (a) simülasyon sonucu (b) ölçüm sonucu

Şekil 8a incelendiğinde, antenin simülasyon sonucunda S11 değeri 5,47 GHz'de yaklaşık olarak -16,97 dB iken, MTM yapısı eklendikten sonra bu değerin -18,31 dB'ye düştüğü görülmektedir. Ayrıca, antenin bant genişliği $146 \mathrm{MHz}$ 'den 153,5 MHz'e yükselmiştir. Üretimi yapılan anten ve üzerine yerleştirilen 1 MTM yapısının S11 değeri 5,23 GHz'de -20,11 dB olarak ölçülmüştür. Diğer taraftan, yönlülük, verim ve kazancin belirlenmesi için antenin 2 boyutlu ve 3 boyutlu ışıma örüntüleri önemlidir.

Şekil 9'da anten ve 1 MTM yapısının üç boyutlu yönlülük ve kazanç 1şıma eğrileri verilmiştir. Antenin, MTM olmadan yönlülüğü $6,65 \mathrm{dBi}$, kazanc1 1,19 dB iken, 1 MTM eklendikten sonra yönlülüğü 9,09 dBi, kazancı 4,12 dB olmuştur. Böylece, MTM yapısı kullanılarak antenin yönlülüğü ve kazancı artırılmıştır. Ayrıca, anten ve 1MTM yapının tek yönde 1şıma yaptığı görülmektedir.

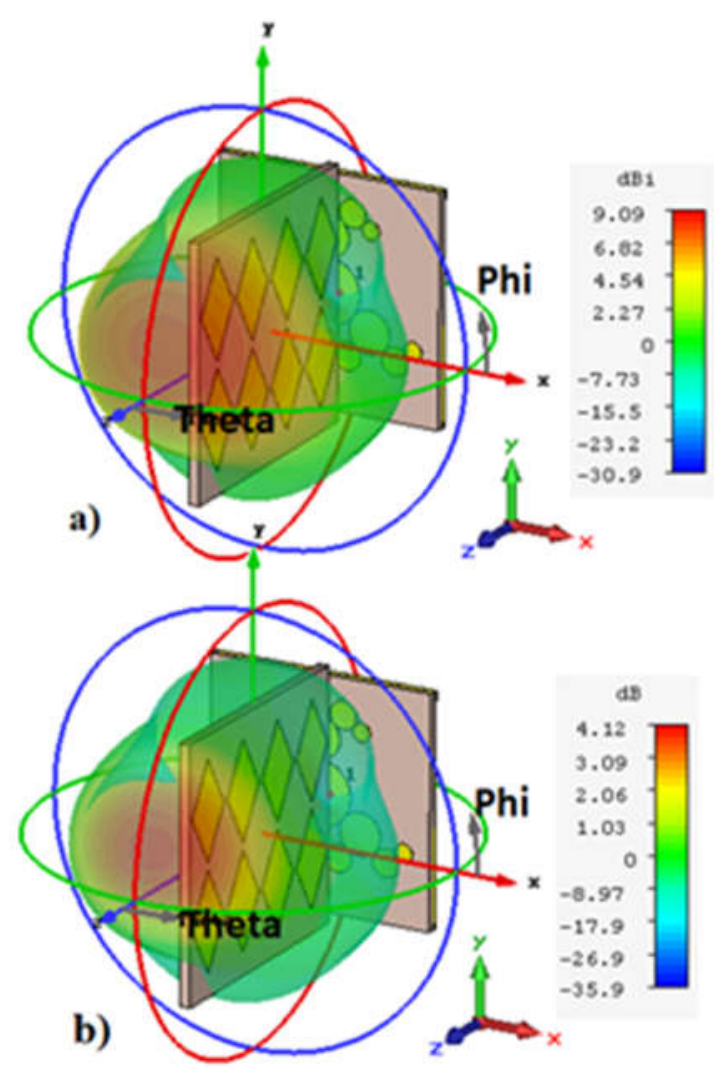

Şekil 9. Anten ve 1MTM yapının üç boyutlu (3D) 1şıma eğrisi; (a) yönlülük, (b) kazanç

Şekil 10a'da üzerine 1 MTM yapısı eklenmiş antenin sayısal olarak elde edilmiş 2 boyutlu ışıma eğrisi görülmektedir. Antenin, $\mathrm{Phi}=0$ derecede, MTM konulmadan ana loblardaki ışıma büyüklüğü 4,85 dBi, hüzme açısı 87,3 derecedir. Anten üzerine 1 MTM yapısı eklendikten sonra, ana lobundaki 1şıma büyüklüğü $8,17 \mathrm{dBi}$, yan lobundaki 1şıma büyüklüğü $-9,4 \mathrm{~dB}$ ve hüzme açıs1 ise 64,4 derece olarak elde edilmiştir. Şekil 10b'de üzerine 1 MTM yapısının yerleştirilmiş antenin ölçülen 2 boyutlu 1şıma eğrisi görülmektedir. Şekil 10b incelendiğinde, üzerine 1 MTM yapısının yerleştirilmiş antenin yan loblarının küçüldüğü, ana lob yönünde 1şımanın arttığı ve sonuç olarak MTM yapısının antenin yönlülüğünü ve kazancını arttırdığı görülmektedir. Ayrıca, sayısal olarak elde edilen sonuçlar ile ölçüm sonuçlarının uyum içerisinde olduğu görülmektedir. 

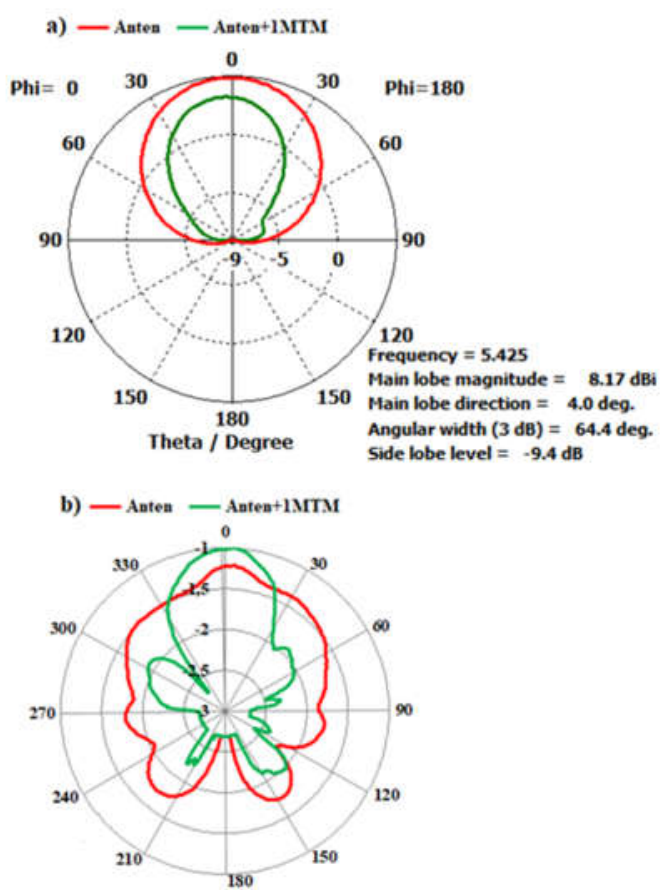

Şekil 10. Anten ve 1MTM yapının 2 boyutlu ışıma eğrisi (a) simülasyon sonucu (b) ölçüm sonucu (normalize)

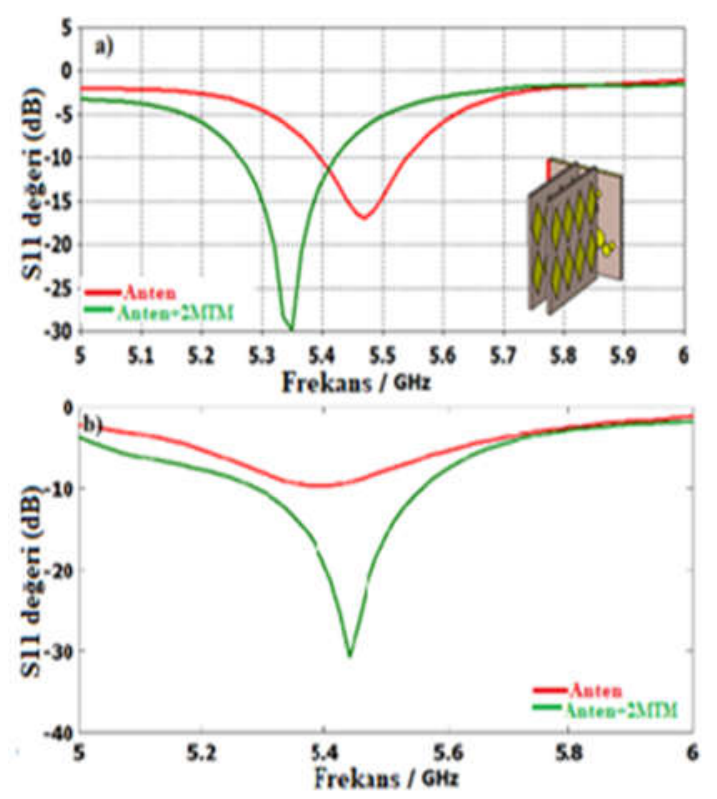

Şekil 11. Anten ve 2 MTM yapının S11 grafiği (a) simülasyon sonucu (b) ölçüm sonucu
Anten üzerine 2 MTM yapı Şekil 11a'da görüldüğü gibi yerleştirilerek yansıma katsayısının (S11) sayısal ve ölçüm grafikleri elde edilmiştir. Anten üzerine yerleştirilen 2 MTM arasındaki mesafe 7,40 mm olarak ayarlanmıştır. Yeni yapının S11 değeri 5,35 GHz'de -29,873 dB'ye düşmüş ve bant genişliği $156,3 \mathrm{MHz}$ olmuştur. Üretimi gerçekleştirilen bu yapının 5,44 GHz'de ölçülen S11 değeri $-30,749$ dB olarak bulunmuştur.

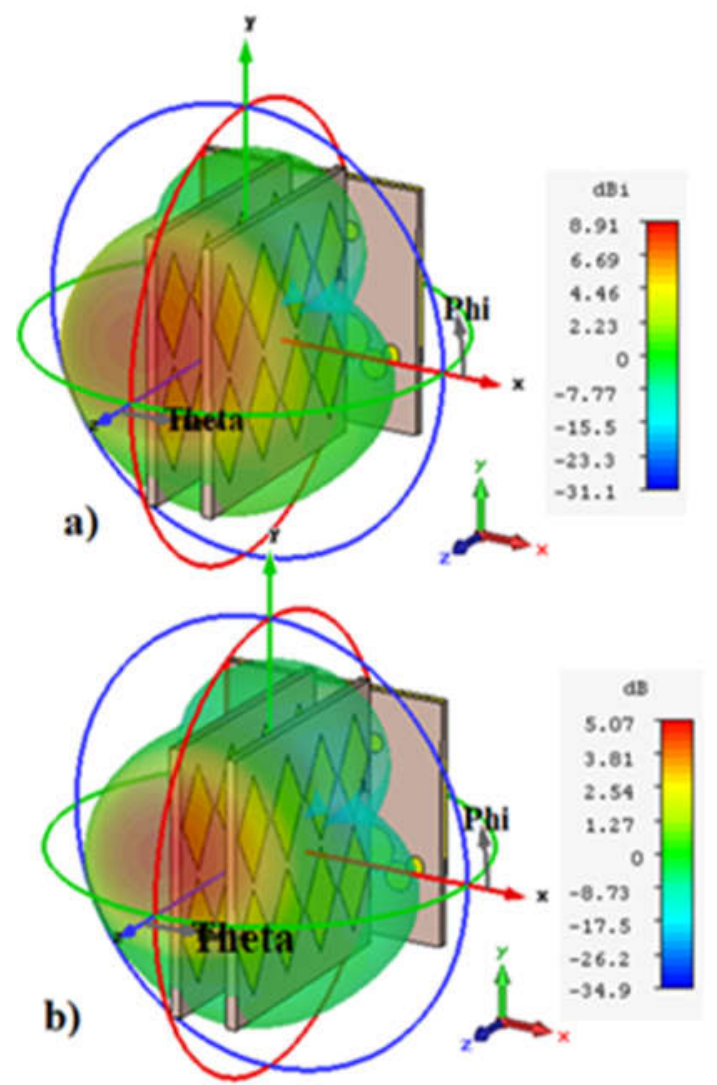

Şekil 12. Anten ve 2 MTM yapının üç boyutlu (3D) 1şıma eğrisi; (a) yönlülük, (b) kazanç

MTM olmadan antenin yönlülüğü $6,65 \mathrm{dBi}$, kazancı 1,19 dB olarak elde edilmişti, ancak antenin üzerine 2 MTM yapısı yerleştirildikten sonra kazancı 5,07 dB, yönlülüğü 8,91 dBi’ye yükselmiştir. 2 MTM yapısı yerleştirilmiş antenin üç boyutlu yönlülük ve kazanç grafiği Şekil 12'de 
görülmektedir. Şekilde, yayılım beklendiği gibi tek yönde olduğu açıkça görülmektedir.

Üzerine 2MTM yapı eklenmiş antenin, 2 boyutlu ışıma örüntüsü Şekil 13'de verilmiştir. Şekil 13a'da görüldüğü gibi ana lobun 1şıma büyüklüğü $7,74 \mathrm{dBi}$, yan lobun ışıma seviyesi - 15,9 dB ve hüzme açısı 64,9 derecedir. Diğer taraftan, üretimi gerçekleştirilen bu yapının ölçülen 2 boyutlu ışıma örüntüsü Şekil 13b'de verilmiş̧ir. Anten üzerine yerleştirilen 2 MTM yapının antenin ana lobundaki 1şıma büyüklüğünü arttırdığı, yan loblardaki 1şıma büyüklüğünü azalttığı, ayrıca antenin yönlülüğünü ve kazancını da artırdığı görülmektedir.
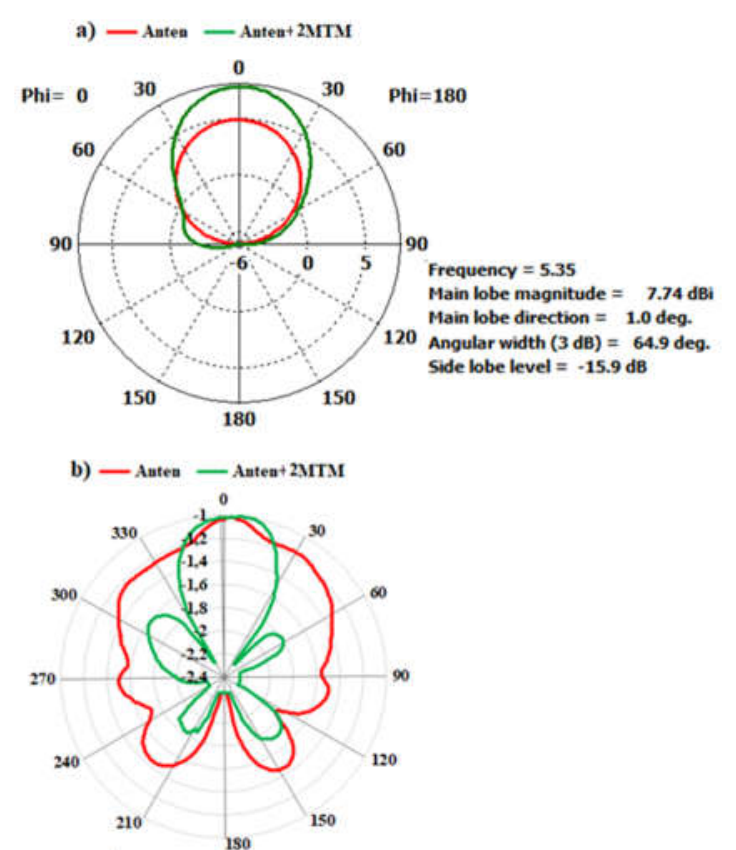

Şekil 13. Anten ve 2 MTM yapının 2 boyutlu ı̧̧ıma eğrisi (a) simülasyon sonucu (b) ölçüm sonucu (normalize)

Anten üzerine $7,40 \mathrm{~mm}$ aralıkla, 3MTM yapısı yerleştirildiğinde; sayısal olarak elde edilen S11 değeri $5,32 \mathrm{GHz}$ 'de $-29,57 \mathrm{~dB}$, bant genişliği ise 159,2 MHz olarak Şekil 14'de görülmektedir. Diğer taraftan, üretilen yeni yapınn S11 değeri ise 5,275 GHz'de -43,119 dB ölçülmüştür.

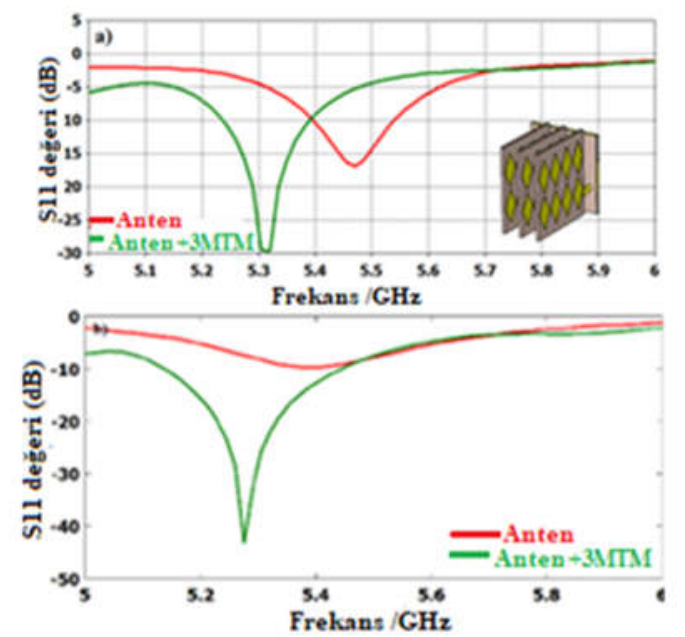

Şekil 14. Anten ve 3 MTM yapının S11 grafiği (a) simülasyon sonucu (b) ölçüm sonucu

Üzerine 3 MTM yapısı yerleştirilmiş antenin üç boyutlu yönlülük ve kazanç grafiği Şekil 15 'de görülmektedir. MTM olmadan 1,19 dB olan anten kazanc1, 3 MTM yapısı yerleştirildikten sonra 5,15 dB'ye, yönlülüğü ise $6,65 \quad \mathrm{dBi}$ 'den 9,23 dBi'ye yükselmiştir.

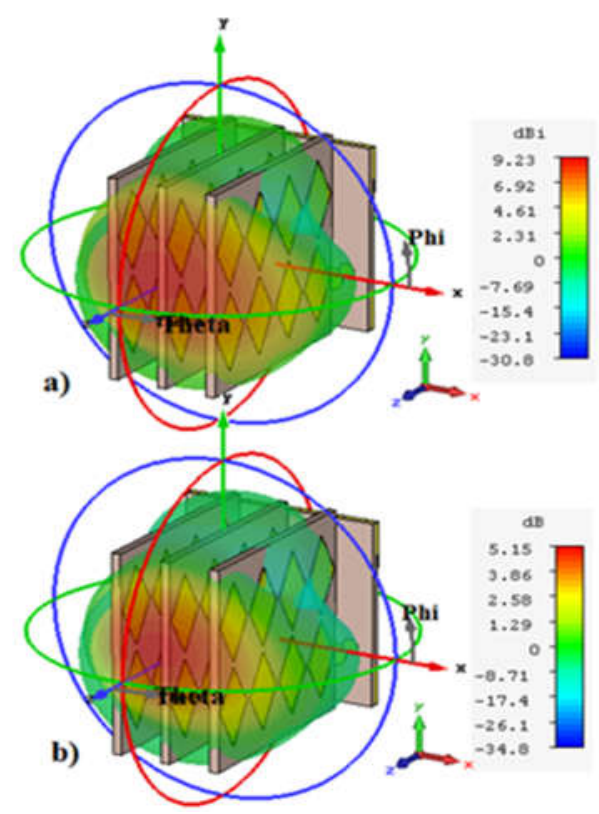

Şekil 15. Anten ve 3 MTM yapının üç boyutlu (3D) 1şıma eğrisi; (a) yönlülük, (b) kazanç 


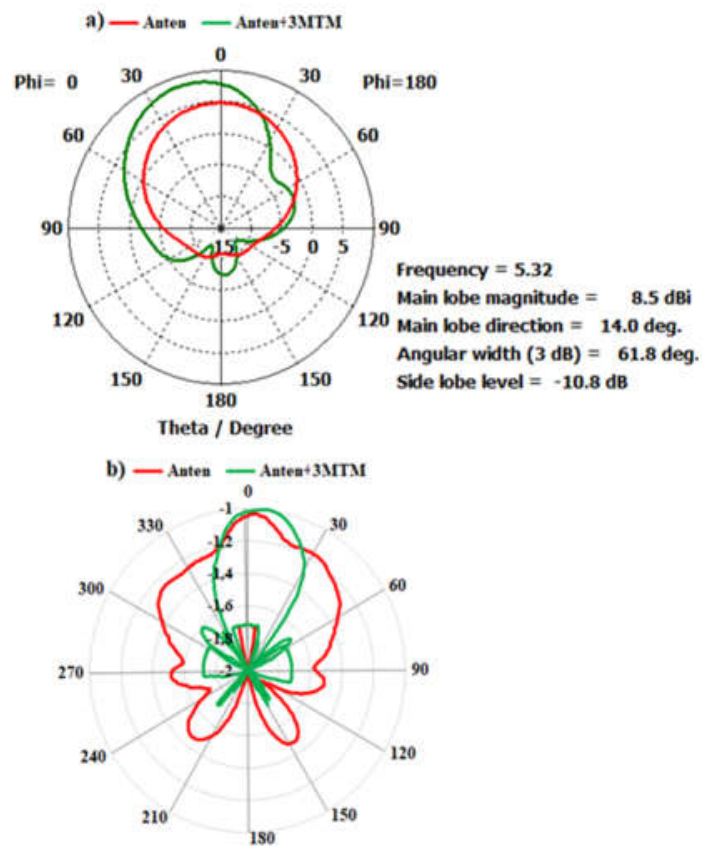

Şekil 16. Anten ve 3 MTM yapının 2 boyutlu ışıma eğrisi (a) simülasyon sonucu (b) ölçüm sonucu (normalize)

Şekil 16'da görüldüğü gibi, $\mathrm{Phi}=0$ derecede ana lobdaki 1şıma büyüklüğü $8,5 \mathrm{dBi}$, yan lobdaki 1şıma -10,8 dB seviyesindedir. Ayrıca, hüzme açısı 87,3 dereceden 61,8 dereceye düşmüştür. Ölçüm sonucunda elde edilen 2 boyutlu ışıma örüntüsüne bakıldığında hem yönlülüğün, hem de kazancın önemli ölçüde arttırdığı ve 1şımanın tek yönde olduğu görülmektedir. Sonuçlardan da anlaşıldığ 1 gibi, üretim ve simülasyon sonuçları uyum içerisindedir.

$\mathrm{Bu}$ bölümde, anten üzerine yerleştirilen MTM yap1s1, anten yüzeyine dik konumda kalacak şekilde 90 derece çevrilerek simülasyon ve ölçümler tekrarlanmıştır. MTM yapı Şekil 8'de verilen yapıya göre 90 derece döndürüldüğünde; 5,425 GHz'de yansıma katsayısının (S11) sayısal ve ölçüm değerleri sırasıyla $-22,376$ ve $-13,678$ olarak elde edilmiştir. Şekil 17'de, MTM yapının etkisiyle S11 değerinin önemli ölçüde azaldığı ve bant genişliğinin ise yaklaşık olarak $167,4 \mathrm{MHz}$ olduğu görülmektedir.

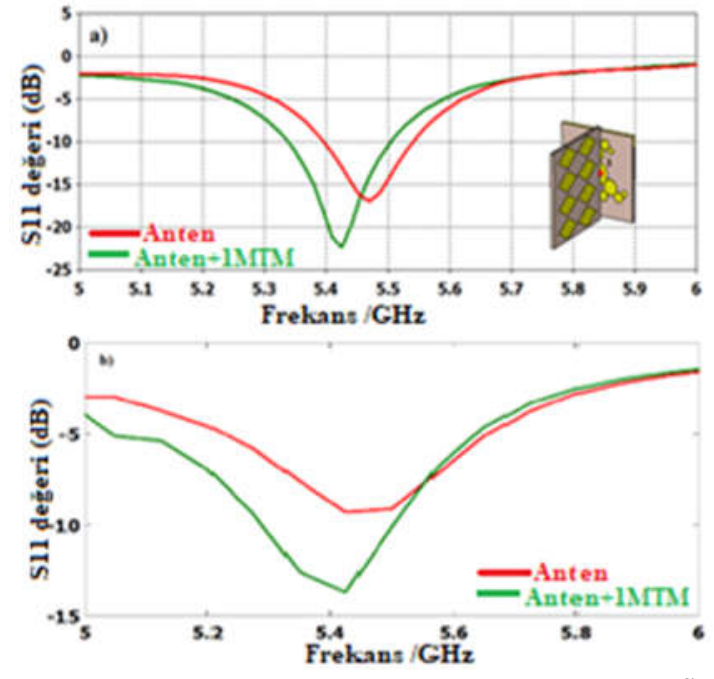

Şekil 17. Anten ve 1 MTM yapının S11 grafiği (a) simülasyon sonucu (b) ölçüm sonucu

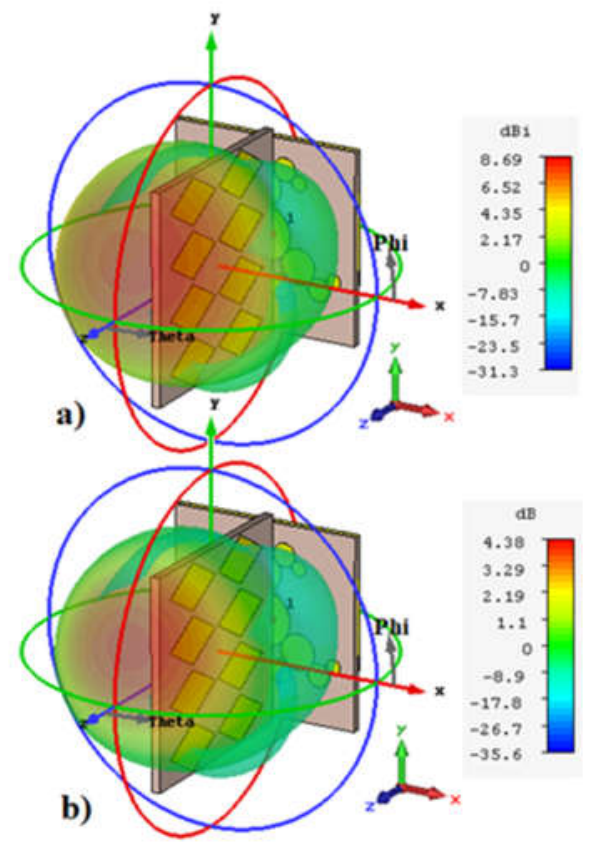

Şekil 18. Anten ve 1MTM yapının üç boyutlu (3D) 1şıma eğrisi; (a) yönlülük, (b) kazanç

Şekil 18, üzerine 1 MTM yapısı yerleştirilmiş antenin üç boyutlu yönlülük ve kazanç grafiğini göstermektedir. Görüldüğü gibi, üzerinde MTM 
olmadan 1,19 dB olan anten kazanc1, MTM yapis1 yerleştirildikten sonra 4,38 dB'ye, yönlülüğü ise 6,65 dBi'den 8,69 dBi'ye çıkmıştır.

Üzerine MTM yerleştirilmiş fraktal antenin simülasyon ve ölçüm sonucunda elde edilen 2 boyutlu ışıma eğrisi Şekil 19'da verilmiş̧ir. Simülasyon sonucuna göre, $\mathrm{Phi}=0$ derecede ana lobdaki ışıma büyüklüğü $7,75 \mathrm{~dB}$, hüzme açısı ise 74,0 derecedir ve yan loblarda 1şıma görülmemektedir. Ölçüm sonuçlarına göre, MTM yapının antenin yan loblarını azalttığı ve ana lobundaki 1şımayı arttırdığı görülmektedir. Ayrıca, MTM yapının antenin yönlülüğünü ve kazancını da arttırdı̆̆g görülmektedir.
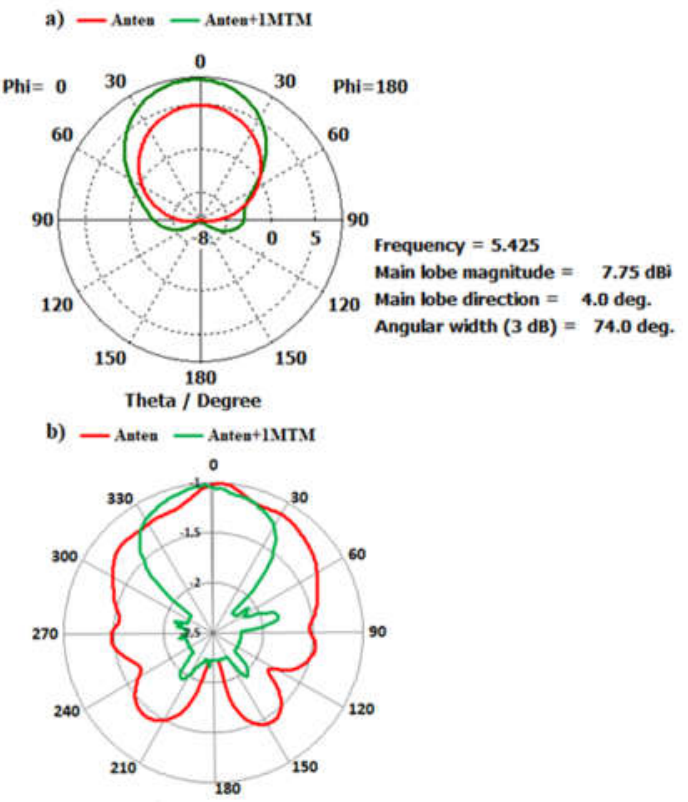

Şekil 19. Anten ve 1 MTM yapının 2 boyutlu 1şıma eğrisi (a) simülasyon sonucu (b) ölçüm sonucu (normalize)

2 adet MTM yapı anten üzerine Şekil 20'de görüldüğü gibi yerleştirildiğinde; Simülasyon sonuçlarına göre, 5,365 GHz'de S11 değeri $-25,908 \mathrm{~dB}$ 'ye düşmüş ve bant genişliği $183,5 \mathrm{MHz}$ olarak gerçekleşmiştir. Üretilen yeni yapının ölçülen S11 değeri ise 5,5 GHz'de $-18,134 \mathrm{~dB}$ olmuştur.
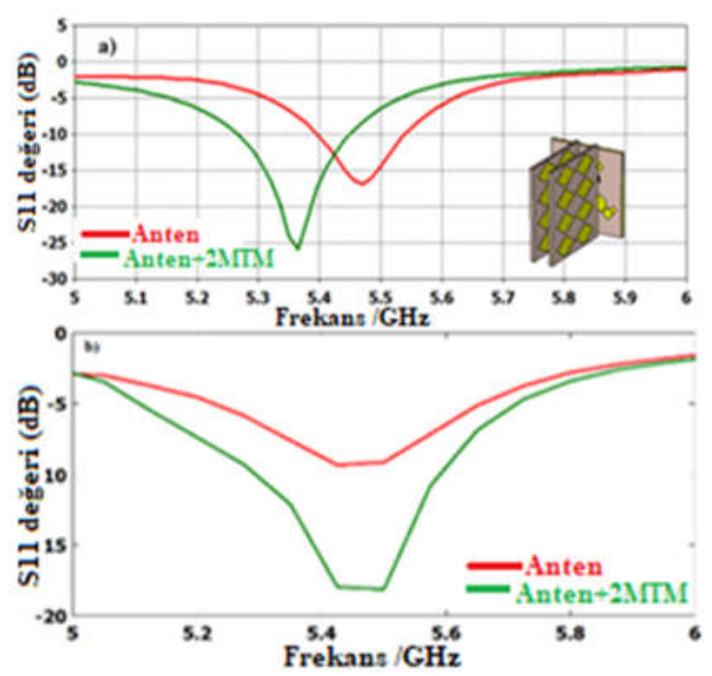

Şekil 20. Anten ve 2 MTM yapının S11 grafiği (a) simülasyon sonucu (b) ölçüm sonucu

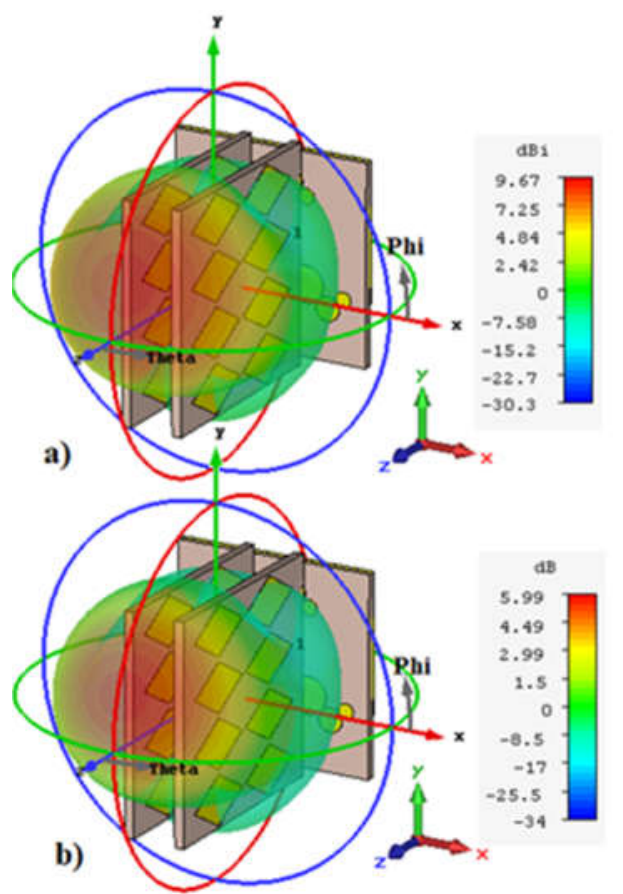

Şekil 21. Anten ve 2 MTM yapının üç boyutlu (3D) 1şıma eğrisi; (a) yönlülük, (b) kazanç

Üzerine 2 adet MTM yapı yerleştirilmiş antenin üç boyutlu yönlülük ve kazanç grafiği Şekil 21'de görülmektedir. MTM olmadan 1,19 dB olan anten 
kazancı, 2 adet MTM yapı yerleştirildikten sonra 5,99 dB'ye, yönlülük ise 9,67 dBi'ye yükselmiştir ve 1şıma beklendiği gibi tek yönde olmuştur.

Fraktal anten ve üzerine yerleştirilmiş 2 MTM yapının etkileşimi neticesinde elde edilen 2 boyutlu 1şıma eğrisinin sayısal ve ölçüm sonuçları Şekil 22'de verilmiştir. Şekil 22 incelendiğinde, Phi $=0$ derecede, MTM olmadan $4,85 \mathrm{dBi}$ olan ana lobun 1şıma büyüklüğü, 2 adet MTM yapı yerleştirildikten sonra 8,63 dBi'ye yükseldiği, yan lobundaki 1şıma miktarının ise $-12,2 \mathrm{~dB}$ olduğu görülmektedir. Ayrıca, hüzme açıs1 87,3 dereceden 65,0 dereceye düşmüştür.

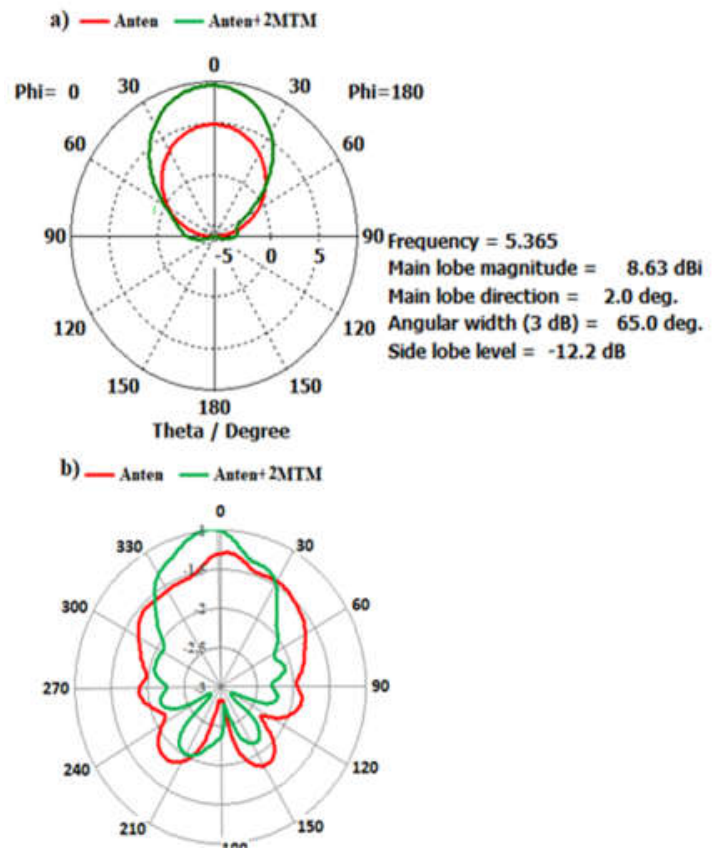

Şekil 22. Anten ve 2 MTM yapının 2 boyutlu 1şıma eğrisi (a) simülasyon sonucu (b) ölçüm sonucu (normalize)

Üç adet MTM yapı yerleştirilmiş anten için yansıma katsayısı (S11) Şekil 23'de verilmiştir. Simülasyon sonuçlarına göre, 5,44 GHz'de S11 değeri -38,024 dB'ye düşmüş ve bant genişliği 172 $\mathrm{MHz}$ olarak gerçekleşmiştir. Üretilen yeni yapının ölçülen S11 değeri ise 5,425 GHz'de -29,923 dB olarak gerçekleşmiştir.

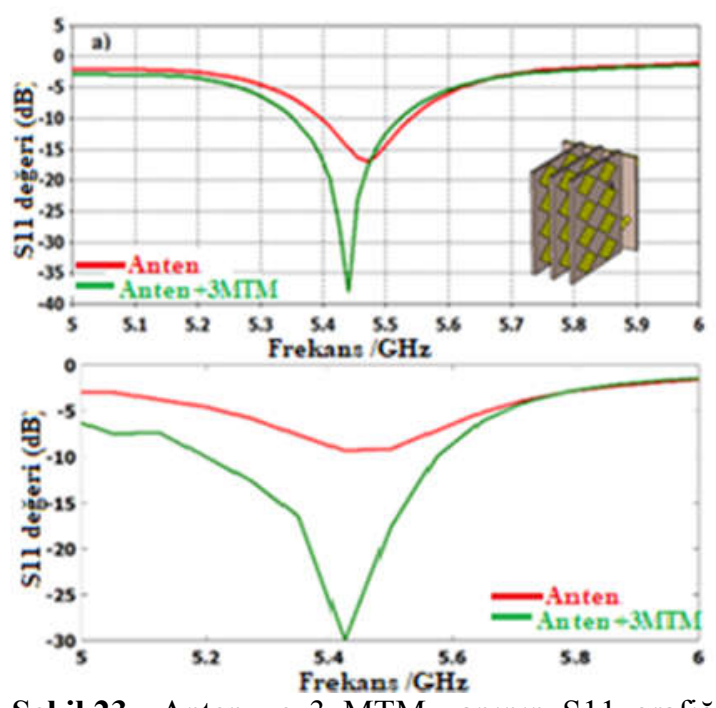

Şekil 23. Anten ve 3 MTM yapının S11 grafiği (a) simülasyon sonucu (b) ölçüm sonucu

$\mathrm{Bu}$ yeni konfigürasyonun üç boyutlu yönlülük ve kazanç grafiği Şekil 24'de görülmektedir. Şekil 24 incelendiğinde, MTM yapıları eklenerek antenin kazanc1 1,19 dB'den 4,79 dB'ye yönlülüğü 6,65 dBi'den 8,93 dBi'ye yükselmiştir.

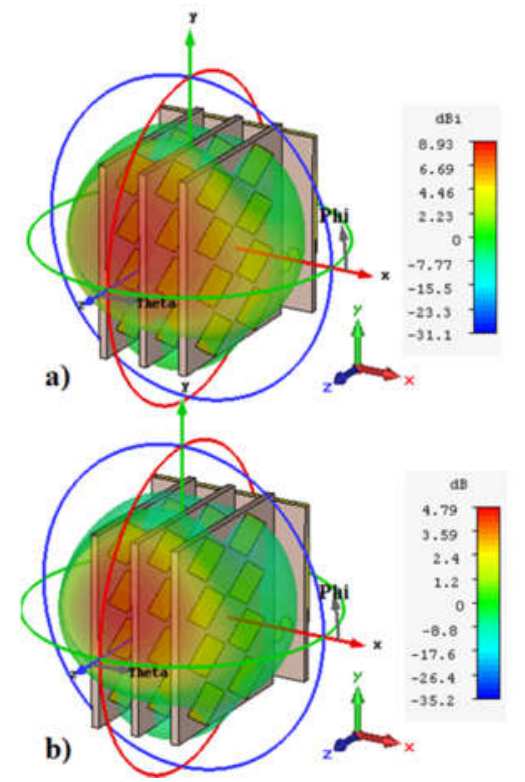

Şekil 24. Anten ve 3 MTM yapının üç boyutlu (3D) 1şıma eğrisi; (a) yönlülük, (b) kazanç 
Fraktal anten ve MTM yapının sayısal ve ölçüm sonucunda elde edilen 2 boyutlu 1şıma eğrisi Şekil 25'de görülmektedir. Şekil 25'de görüldüğü gibi, Phi=0 derecede ana lobdaki 1şıma büyüklüğü $7,74 \mathrm{dBi}$, yan lobdaki 1şıma $-8,1 \mathrm{~dB}$ seviyesinde ve hüzme açısı ise 72 derecedir. Ölçüm sonuçları incelendiğinde, MTM yapısının antenin yan loblarını azalttığı ve ana lobundaki 1şımayı arttırdığı anlaşılmaktadır.
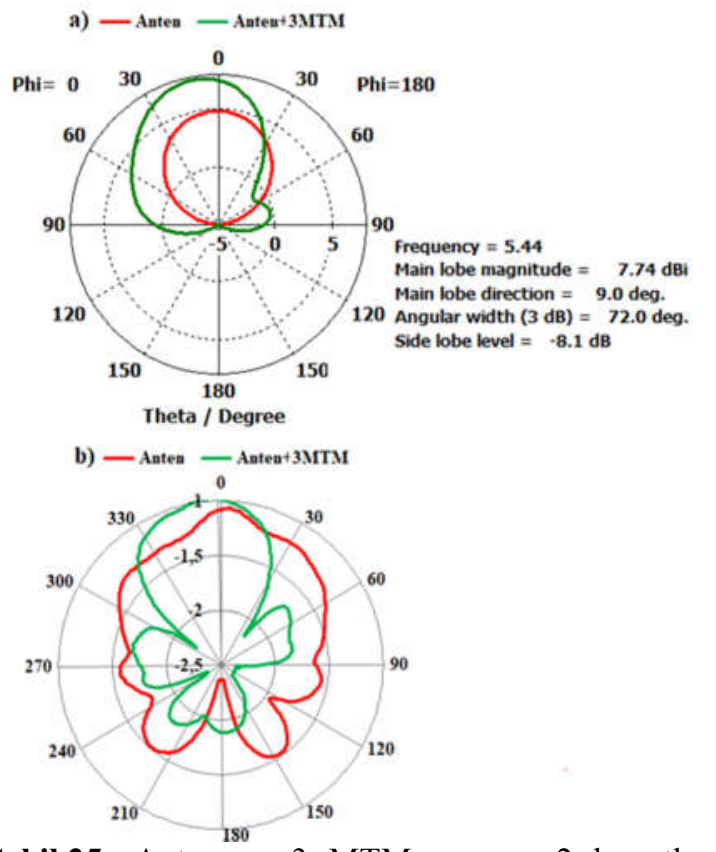

Şekil 25. Anten ve 3 MTM yapının 2 boyutlu 1şıma eğrisi (a) simülasyon sonucu (b) ölçüm sonucu (normalize)

\section{SONUÇ}

5,47 GHz'de çalışan $35 \mathrm{~mm}$ x $35 \mathrm{~mm}$ boyutlarında dairesel şekillerden oluşmuş bir fraktal anten tasarlanmıştır. MTM yapısı ise $38 \mathrm{~mm}$ x $38 \mathrm{~mm}$ boyutunda $2 \times 4$ periyodik olarak sıralanmış eşkenar dörtgenlerden oluşmaktadır. MTM yapılar anten üzerine 90 derece gelecek şekilde, farklı sayıda yerleştirilmiş ve analiz edilmiştir. Simülasyonu ve ölçümü yapılan konfigürasyonların hem yansıma katsayısı (S11), hem de 1şıma örüntüleri incelenmiş ve karşılaştırılmıştır. $\mathrm{Bu}$ çalışmada incelenen konfigürasyonların özet sonuçları
Çizelge 2'de listelenmiştir. Simülasyon sonuçlarına göre, MTM olmadan antenin yansıma katsayısı, S11 değeri 5,47 GHz'de -16,947 dB, yönlülüğü $6,65 \mathrm{dBi}$, kazanc1 $1,19 \mathrm{~dB}$, ana lobundaki 1şıma büyüklüğü 4,85 dBi olarak elde edilmiştir. 2 MTM yap1 anten üzerine yerleştirildiğinde, simülasyon sonucunda elde edilen S11 değeri 5,365 GHz'de -25,908 dB, yönlülüğü $9,67 \mathrm{dBi}$, kazanc1 $5,99 \mathrm{~dB}$, ana lobundaki 1şıma büyüklüğü $8,63 \mathrm{dBi}$, bant genişliği 183,5 MHz'e yükselmiştir. Hüzme açısı ise 65 derecedir. Üretimi gerçekleştirilen Anten +2MTM yapısının S11 değeri ise 5,5 GHz'de $-18,134$ dB'ye düşmüştür. MTM yapıları eklendikten sonra rezonans frekansında meydana gelen kaymalar, MTM yapı ile anten arasındaki etkileşimden kaynaklanmaktadır.

Çizelge 2. Özet simülasyon sonuçları

\begin{tabular}{|c|c|c|c|c|}
\hline \multicolumn{5}{|c|}{ ANTEN } \\
\hline Görünūș & Frekans & $\begin{array}{l}\text { Geri dönüş } \\
\text { kaybı }\end{array}$ & Kazanç & Directivity \\
\hline & $5.47 \mathrm{GHz}$ & $-16.947 \mathrm{~dB}$ & $1.19 \mathrm{~dB}$ & $6.65 \mathrm{dBi}$ \\
\hline \multicolumn{5}{|c|}{ Üzerinde bir katman MTM bulunan fraktal anten parametreleri } \\
\hline & $5.425 \mathrm{GHz}$ & $-18.311 \mathrm{~dB}$ & $4.12 \mathrm{~dB}$ & $9.09 \mathrm{dBi}$ \\
\hline & $5.425 \mathrm{GHz}$ & $-22.376 \mathrm{~dB}$ & $4.38 \mathrm{~dB}$ & $8.69 \mathrm{dBi}$ \\
\hline \multicolumn{5}{|c|}{ Üzerinde iki katman MTM bulunan fraktal anten parametreleri } \\
\hline & $5.35 \mathrm{GHz}$ & $-29.873 \mathrm{~dB}$ & $5.07 \mathrm{~dB}$ & $8.91 \mathrm{dBi}$ \\
\hline & $5.365 \mathrm{GHz}$ & $-25.908 \mathrm{~dB}$ & $5.99 \mathrm{~dB}$ & $9.67 \mathrm{dBi}$ \\
\hline \multicolumn{5}{|c|}{ Üzerinde üç katman MTM bulunan fraktal anten parametreleri } \\
\hline & $5.32 \mathrm{GHz}$ & $-29.576 \mathrm{~dB}$ & $5.15 \mathrm{~dB}$ & $9.23 \mathrm{dBi}$ \\
\hline & $5.44 \mathrm{GHz}$ & $-38.024 \mathrm{~dB}$ & $4.79 \mathrm{~dB}$ & $8.93 \mathrm{dBi}$ \\
\hline
\end{tabular}

Ölçüm ve simülasyon sonuçları uyum içerisindedir. Sonuçlar incelendiğinde, önerilen yapının antenin yönlülügüün, kazancını ve verimliliğini artırdığı anlaşılmaktadır. Ölçüm ve 
simülasyon sonuçları arasında gözlenen farklılıklar üretim ve ölçüm hatalarından kaynaklanmaktadır.
Conference on Microwave and Millimeter Wave Technology, 400-402.

\section{KAYNAKLAR}

1. Çelik, K., Kurt, E., 2018. Design and Simulation of the Antenna for RF Energy Harvesting Systems. $6^{\text {th }}$ International Istanbul Smart Grids and Cities Congress and Fair (ICSG), 148-150.

2. Hirway, H., Shaikh, T., 2018. Comparison of Low Profile Sierpinski and Koch Fractal Antenna for Wireless Application. Proceeding of 2018 IEEE Int. Conference on Current Trends Toward Converging Technologies, Coimbatore, India, 1-6.

3. Mete, C., 2011. Minkowski Fraktal Anten Tasarımı ve Yapay Sinir Ağı Modeli. Yıldız Teknik Üniversitesi, FBE, Yüksek Lisans Tezi, s75, İstanbul.

4. Jena, M., Mangaraj, B., Mishra, D., 2013. Bandwith and Gain Enhancement of Multiband Fractal Antenna Based on the Sierpinski Carpet Geometry. ICTACT Journal on Communication Tech., 669-674.

5. Sivia, J., Bhatia, S., 2015. Design of Fractal Based Microstrip Rectangular Patch Antenna for Multiband Applications. 2015 IEEE Int. Advance Computing Conference (IACC), 712-715.

6. Gupta, M., Mathur, V., 2018. Hexagonal Fractal Antenna Using Koch for Wireless Applications, Frequenz 2018, 443-453.

7. Safia, O., Eleftheriades, G., 2018. A New Gosper Island Fractal UWB Monopole Antenna with Enhanced Bandwidth Characteristics. IEEE Int. Symposium on Antennas and Propagation \& USNC/URSI National Radio Science Meeting, 1043-1044.

8. Madhav, B., Reddy, V., Rajasekar Reddy, D., Sankar, K., Ramanujan, E., Prakash, V., Rao, M., 2018. Tree Shaped Fractal Antenna with Multiband Characteristics. International Journal of Engineering and Technology, 333-338.

9. Yong, W., Shaobin, L., 2008. A New Modified Crown Square Fractal Antenna. In 2008 Int 